\title{
Comparison \& Magnitude Credibility: Whom to Trust When Reports are Conflicting?
}

\author{
Shuhua Zhou, ${ }^{1, *}$, Hongzhong Zhang ${ }^{2}$ and Bin Shen ${ }^{1}$ \\ ${ }^{I}$ College of Communication \& Information Sciences, University of Alabama, USA; ${ }^{2}$ School of Art \& Communication, \\ Beijing Normal University, Beijing, China
}

\begin{abstract}
This study used the concepts of comparison credibility and magnitude credibility to assess perceived news media credibility in China. It also investigated which sources people trusted more when they encountered conflicting reports regarding different kinds of stories including entertainment news, disaster news and political news. A random sample from three major metropolises $(n=1,844)$ were telephone interviewed. Results indicated that television was perceived as the most trustworthy. Regardless of the type of stories, people trusted national Chinese media over other media outlets. Implications on credibility research are discussed.
\end{abstract}

Keywords: Channel credibility, Chinese media, conflicting information, media credibility.

\section{COMPARISON \& MAGNITUDE CREDIBILITY: WHO TO TRUST WHEN REPORTS ARE CONFLICT- ING?}

The latest issue of World Press Freedom Index ranks China as one of the countries with the least respect for media freedom (Reporters Without Borders, 2013). Meanwhile, the Chinese government actively promotes a credible and impartial image by loosening government censorship over news content, advancing international journalism and foreign broadcasting, and supporting market-oriented media organizations. Three leading state-run media organizations, namely, CCTV, Xinhua News Agency, and the People's Daily, received 45 billion RMB ( $\$ 7$ billion USD) from the government in 2009 to upgrade their facilities, to train staff and to extend their global reach (MacMurchy, 2009). However, critics maintain that China shows no sign of improving and that "China can't buy itself credibility. Not even for 45 billion (MacMurchy, 2009)". Academic research into the credibility of Chinese news media is therefore warranted, beginning with the Chinese audience they serve.

The present study purports to examine perceived credibility of Chinese news media by using the concepts of comparison credibility and magnitude credibility. Comparison credibility is used more often and asks participants to rank, in order, the most credible sources. Magnitude credibility is used less frequently and asks respondents to assign an absolute value to a media source. As the first focus, this paper investigates the implications of these credibility measures. As a second focus, we also want to examine which news sources are trusted more by Chinese audiences in cases where reports are conflicting in regard to different types of news stories, namely, entertainment news,

*Address correspondence to this author at the College of Communication \& Information Sciences, University of Alabama, USA;

Tel: 205-348-8653; Fax: 205-348-6774; E-mail: szhou@ua.edu disaster news and political news. Obviously, these types of stories carry different weight in terms of life consequences; disaster news is about life and death, political news is about ideology and entertainment news is about leisure consumption. Do the different implications affect credibility perception? Today, no research to our knowledge has been conducted to investigate these issues.

In this study, audience assessment of perceived media credibility is examined in two ways. People are first asked to choose the most credible medium among several media types. They are then invited to score the credibility of each media channel. The two measures are also used across message types under the premise that conflicting reports are present.

\section{LITERATURE REVIEW}

Media credibility has generally been examined from three different perspectives: channel credibility, source credibility, and message credibility (Kiousis, 2001; Metzger, Flanagin, Eyal, Lemus \& McCann, 2003). The advent of diverse mass media vehicles has expanded the context in which channel credibility is studied. Channel credibility, initially and commonly studied by the media industry, focuses on the trustworthiness and believability of a particular medium (Gaziano \& McGrath, 1986; Kiousis, 2001).

Extant research has produced mixed results regarding which type of media is the most credible vehicle of news and information. While users in several studies viewed television as more credible than newspapers (Gaziano \& McGrath, 1986; Mendelli \& Vianello, 2010; Wesley \& Severin, 1964), the latest report on Americans' confidence in institutions, released by Gallup (2011), showed that almost the same percentage of American people expressed "a great deal" or "quite a lot" of confidence toward newspapers and television. Researchers have also examined many other 
factors to determine how audiences attributed their trust to different media channels, such as media characteristics (Hovland \& Weiss, 1951; Westerman, Spence \& Van Der Heide, 2013) accuracy and fairness (Gaziano \& McGrath, 1986; Jensen \& Hurley, 2012), and user information (Wesley \& Severin, 1964; Yuan, 2011).

The emergence and popularity of the Internet and social media have complicated this area of research. Recently Johnson and Kaye (2000) found that online sources were perceived as more believable, accurate, in-depth, and fair than traditional media. Furthermore, Flanagin and Metzger (2007) identified a positive relationship between online reliance and perceived credibility. In Kiousis's (2001) study, however, respondents rated newspapers as the most trustworthy, being more trustworthy than online news and television news. Similarly, Schmierbach and Oeldorf-Hirsch (2012) revealed that newspaper stories were considered more credible than those reported via Twitter. Given the mixed findings about channel credibility and the fact that little is known about perceived channel credibility in China, the following research question is proposed:

RQ1: How does the Chinese public perceive the following media in terms of channel credibility: television, newspapers, radio, magazines, websites and mobile devices, as measured in comparison credibility and magnitude credibility? Do any contingent factors, such as education, age and party affiliation, play a role?

Additionally, there is little research comparing the types of stories and the kinds of media sources in which people place their trust (Jensen \& Hurley, 2012). This research lacuna may be a function of neglect, as most research focuses on the attributes of news messages (such as content quality, author credentials, and testimonials) and news sources (such as knowledge, expertise and appearances). There is research, however, that reveals how people treat different kinds of information and have different expectations of accuracy of such differing information. As reported by (Robinson and Kohut, 1988), two Roper surveys showed that when conflicting reports were present, people tended to choose different sources of information. In 1959, $32 \%$ of the respondents preferred to believe newspapers with $29 \%$ preferring TV. However, in a 1986 survey, the trend was reversed. It is possible that audiences may expect certain kinds of stories to be more accurate than other kinds of stories. Much of entertainment news, for example, thrives on sensational news for attention. Political stories, on the other hand, are often carefully crafted to avoid perceived bias, while accuracy in disaster stories has huge implications in crisis situations.

Major and Atwood (1997) studied people's reactions to earthquakes in Southern California and found that mass media played a critical role in disseminating accurate and timely information to protect lives and property. While Southern California residents perceived earthquake announcements from magazines and books as more credible than newspapers and television. Major and Atwood (1997) found that when natural disasters such as earthquake predictions were not accurately covered by the news media, perceived newspaper credibility would decrease significantly but perceived TV and radio credibility would not.
While no credibility comparison studies were found on conflicting reports, many studies did indicate that people preferred certain news sources over others (Chung, Nam, \& Stefanone, 2012); Stroud and Lee (2013) found that audiences preferred exposure to news that supported their political values over those arguing against their positions, which was consistent with many previous research findings. For example, around $40 \%$ of conservative Republicans indicated FOX News as their regular news source, while only $20 \%$ of liberal Democrats said so (Pew Research Center, 2010). It is reasonable to believe that people may find one source to be more trustworthy than another when there are conflicting reports of political happenings.

We, therefore, propose the following research questions:

RQ2: When reports of entertainment news are conflicting, which news source do Chinese people believe the most?

RQ3: When reports of disaster news are conflicting, which news source do Chinese people believe the most?

RQ4: When reports of political news are conflicting, which news source do Chinese people believe the most?

\section{METHODS}

The survey data used for analysis were gathered through a series of telephone interviews conducted between May $29^{\text {th }}$ and June $9^{\text {th }}, 2012$. A professional survey firm in Beijing was hired to conduct the survey. All telephone interviews were administered in survey labs via a computer-assisted telephone interview system (CATI).

\section{Participants}

Participants of this survey were recruited through a random digit dialing technique. To control for disproportioned exposure to non-domestic news sources (such as people in Guangdong having ready access to Hong Kong media) or heavy doses of political information (such as people in the nation's capital), three major cities were first randomly drawn from a host of major cities before the random digit dialing technique was applied to the three area codes. In total, 1,844 Chinese citizens from these three cities (Tianjin, 606, with a response rate of 32.8\%; Chengdu, 618, with a response rate of $27.5 \%$; Nanjing, 620, with a response rate of $26.7 \%$ ) were telephone interviewed for 25-30 minutes individually. Of the Tianjin sample, $41.9 \%(\mathrm{~N}=254)$ were male and $55.4 \%(\mathrm{~N}=336)$ were female. The average age of the participants was 44 years old $(\mathrm{SD}=18) .53 .6 \%$ of them had a college degree, but a small majority of them $(59.7 \%)$ made RMB3,000 (about \$500) or less per month. Approximately $17.8 \%$ of the participants identified themselves as a communist. Of the Chengdu sample, $46.8 \%$ $(\mathrm{N}=289)$ were male and $51.6 \%(\mathrm{~N}=319)$ were female. The average age of the participants was 41 years old $(\mathrm{SD}=19)$. $40.6 \%$ of them had a college degree, but a majority of them (78.7\%) made RMB3,000 (about $\$ 500$ ) or less per month. Approximately $18.6 \%$ of the participants identified themselves as a communist. Of the Nanjing sample, $46.8 \%$ $(\mathrm{N}=289)$ were male and $48.4 \%(\mathrm{~N}=300)$ were female. The average age of the participants was 42 years old $(\mathrm{SD}=17)$. $47.2 \%$ of them had a college degree, but about half of them $(56.0 \%$ ) made RMB3,000 (about $\$ 500$ ) or less per month. 
Approximately $17.1 \%$ of the participants identified themselves as a communist. The percentages of respondents in each city strongly reflected their corresponding demographics in the population. In addition, these samples were rather normal in distribution and comparability.

\section{Measures}

Media credibility has generally been measured in two ways: comparison credibility, and magnitude credibility.

\section{Comparison Credibility}

The comparison measure scale was created by the Roper Organization in 1959. It was initially used in surveys asking American people to evaluate how they perceived various mass media. People were asked to answer the following question: "If you got conflicting or different reports about the same news story from radio, television, the magazines or the newspapers, which of the four versions would you be most inclined to believe - the one on radio or television or magazines or newspapers?" (Roper Organization, 1979). As "one of the most frequently used operational definitions for media source credibility" (Stacks \& Salwen, 2009), this question is applied in the current study to measure channel credibility.

\section{Magnitude Credibility}

Believing that the comparison measurement scale developed by the Roger Organization was biased against newspapers, Carter and Greenberg (1965) revised the original question and developed a magnitude measure scale. Respondents in their studies were prompted, "We would like your opinion about the reliability of television news. If perfect reliability is 100 percent, what percentage of the news on television do you believe?" Similar wordings were applied to others channels such as newspaper, magazine, websites, and mobile devices.

\section{Preferred Sources}

Two sets of questions were asked, each regarding conflicting entertainment, disaster and political news. For example, people were asked to indicate which medium (TV, newspapers, radio, Internet, magazines, mobile devices) they tended to trust if there was conflicting political news. They were also asked which sources (Chinese local media, Chinese national media, HK/Macao/Taiwan media, foreign media, opinion leaders) they tended to trust the most in such situations. The same types of questions were also asked of conflicting entertainment news and disaster news.

Finally, SPSS was used to conduct all data analyses.

\section{RESULTS}

The first research question asked how people perceived the following media in terms of channel credibility: television, newspapers, radio, magazines, websites and mobile devices. The comparison credibility results (see Fig. 1) suggested that most of the respondents indicated TV as most credible (Tianjin: 57.6\%; Chengdu: $54.4 \%$; Nanjing: $57.6 \%$ ), followed by newspapers (Tianjin: $22.8 \%$; Chengdu: 28.1\%; Nanjing: 22.4\%), websites (Tianjin: 15.7\%; Chengdu: 14\%; Nanjing: $16.5 \%$ ), and radio (Tianjin: 2.8\%; Chengdu: 1.2\%; Nanjing: $2.8 \%$ ). Less than $1.5 \%$ of the respondents considered magazines or mobile devices as the most credible medium.

Magnitude credibility reported in Fig. (2) indicates that respondents in all three cities thought television was most credible (Tianjin: 75.12; Chengdu: 73.02; Nanjing: 75.71). Newspapers (Tianjin: 70.33; Chengdu: 69.33; Nanjing: 70.02 ) was rated as the second most credible media channel, followed by radio (Tianjin: 66.92; Chengdu: 62.68; Nanjing: 65.67), websites (Tianjin: 62.92; Chengdu: 58.93; Nanjing: 61.99), magazines (Tianjin: 58.41; Chengdu: 54; Nanjing: 59.43), and mobile devices (Tianjin: 56.72; Chengdu: 52.35; Nanjing: 56.08).

It is worth mentioning that the ranking results of magnitude credibility were exactly the same across the three cities. A phenomenon of particular interest was that while websites were perceived more credible than radio in comparison credibility, the magnitude credibility index

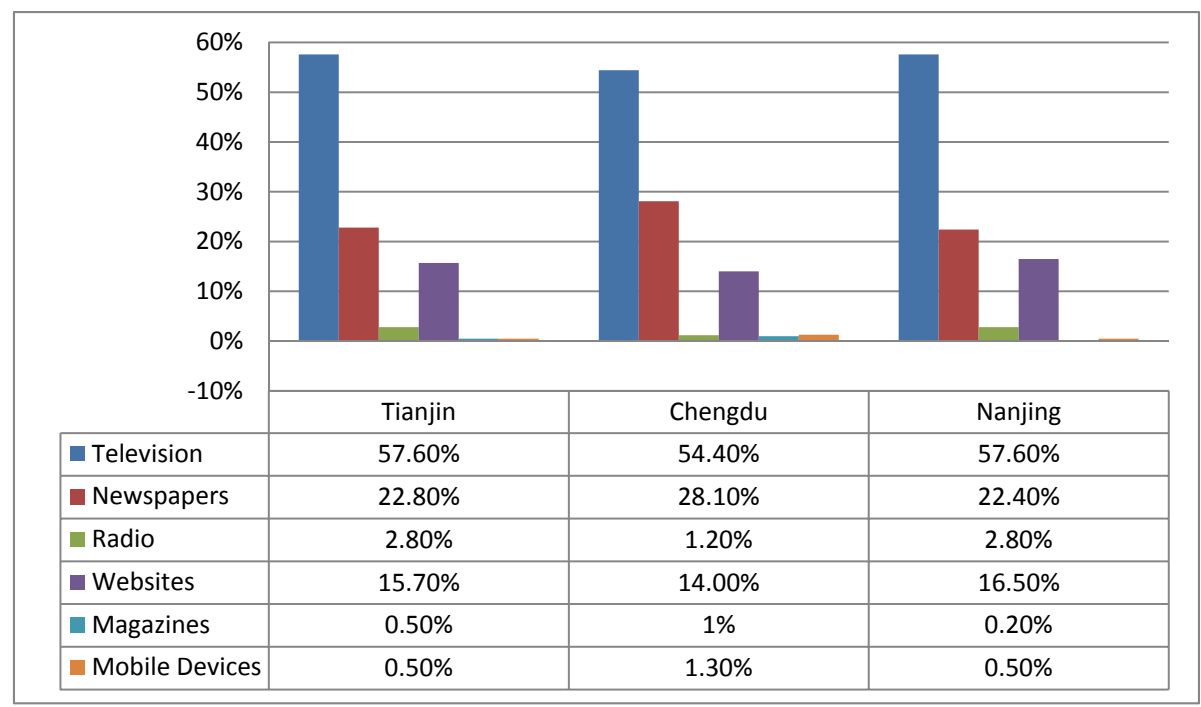

Fig. (1). Percentage of comparison credibility for the six media channels. 


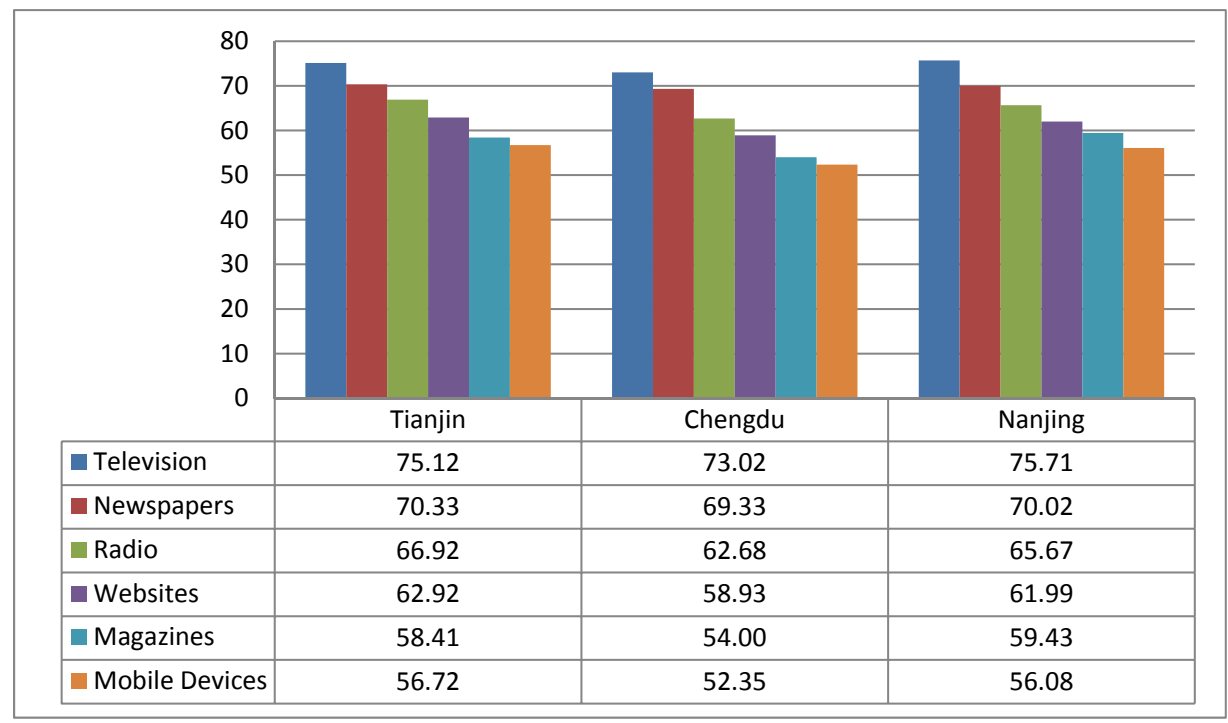

Fig. (2). Means of magnitude credibility for the six media channels.

reversed that order: radio was considered more reliable than websites, raising a measurement issue of which we would discuss later. Since the discrepancy was exactly the same across the three cities, data were combined together to perform a series of t-tests, ANOVAs and chi-square analyses to determine what led to this discrepancy, based on contingent factors such as education, age, and party affiliation.

A $2 \times 4$ chi-square test identified a significant relationship between education level and perceived channel credibility, $X^{2}(3, \mathrm{~N}=1640)=63.825, p<.001$. Because few participants in the survey went to graduate school or had less than primary school education, the category of education level was re-coded into two groups: high school degree or lower, and college or higher. Given that few people perceived radio, magazines or mobile devices to be the most credible media in comparison credibility, the three categories were also combined and re-coded into "other media" for analyses.
Overall, those who considered websites more credible than other media were more likely to hold a college degree or to have more education in general $(22.7 \%$ vs. $8.6 \%$, see Table 1); those who considered TV and newspaper most credible were more likely to have a high school diploma or lower education (61.2\% vs. 50.3\%).

Similary, a $3 \times 4$ chi-square test identified a significant relationship between age level and perceived channel credibility, $X^{2}(6, \mathrm{~N}=1673)=114.573, p<.001$. Age was collapsed into three categories, those who were 30 years old or younger, those 31 to 50 years old, and those more than 50 years old. Two trends emerged, as people aged, they tended to rate newspaper as the most credible and website as less credible (see Table 1).

In addition, a $2 \times 4$ chi-square test yielded a nonsignificant relationship between party membership and perceived channel credibility, $X^{2}(3, \mathrm{~N}=1671)=6.646$, $p=0.084$. Communist party membership did not seem to affect how people perceived credibility (see Table 1).

Table 1. Chi-square analyses \& comparison credibility.

\begin{tabular}{|c|c|c|c|c|}
\hline & TV & Newspaper & Website & Others \\
\hline \multicolumn{5}{|c|}{ Education : $X^{2}(3, N=1640)=63.825, p<.001$} \\
\hline High School & $225(26.0 \%)$ & $529(61.2 \%)$ & $74(8.6 \%)$ & $36(4.2 \%)$ \\
\hline College & $184(23.7 \%)$ & $390(50.3 \%)$ & $176(22.7 \%)$ & $26(3.4 \%)$ \\
\hline \multicolumn{5}{|c|}{ Age $: X^{2}(6, N=1673)=114.573, p<.001$} \\
\hline $30-$ & $152(26.3 \%)$ & $252(46.3 \%)$ & $147(25.4 \%)$ & $27(4.7 \%)$ \\
\hline $31-50$ & $127(20.4 \%)$ & $385(61.8 \%)$ & $93(14.9 \%)$ & $18(2.9 \%)$ \\
\hline $50+$ & $131(27.8 \%)$ & $306(64.8 \%)$ & $18(3.8 \%)$ & $17(3.6 \%)$ \\
\hline \multicolumn{5}{|c|}{ Communist Party Membership : $X^{2}(3, N=1671) 6.64, p=0.084$} \\
\hline Member & $95(29.1 \%)$ & $182(55.8 \%)$ & $38(11.7 \%)$ & $11(3.4 \%)$ \\
\hline Non-Member & $320(23.8 \%)$ & $756(56.2 \%)$ & $217(16.1 \%)$ & $52(3.9 \%)$ \\
\hline
\end{tabular}


Regarding magnitude credibility, either $\mathrm{t}$-tests or ANOVA tests were conducted to identify if education, age and party affiliation played a role.

Education was a factor in rating credibility of television, website and radio. No differences based on this contingent factor were found for newspaper, magazine and mobile devices (see Table 2). Specifically, people with lower education level rated TV $(m=76.72, S D=16.137)$ higher than those with higher education level $(m=72.34$, $S D=18.722, t(1,1,530)=4.919, p=.001)$. They also rated radio $(m=66.87, S D=19.191)$ higher than those with higher education level $(m=64.30, S D=19.705, t(1,1,530)$ $=2.168, p=.03)$. However, they rated website $(m=60.39$, $S D=19.477)$ lower than those with higher education level $(m=62.49, S D=18.029, t(1,1,530)=-2.057, p=.04)$.

In terms of communist party membership, members and non-members were different in rating credibility of website and mobile devices. No differences were found for other media channels (see Table 3). Specifically, member rated website $(m=58.93, S D=19.958)$ lower than non-members $(m=62.09, S D=18.318, t(1,1,530)=-2.498, p=.013)$. They also rated mobile devices $(m=52.51, S D=21.796)$ lower than non-members $(m=56.42, S D=21.333$, $t(1,1,530)=-2.422, p=.016)$. It seemed that members were more suspicious of these newer technologies.

However, one-way ANOVA analyses revealed age was a significant predictor in magnitude credibility ratings on four channels, namely, newspaper, television, website, and mobile devices, while there were no significant differences between magazine and radio. The trends were somewhat consistent with comparison credibility. Specifically, as people age, they tended to rate television as more credible, whereas the reverse was true for website and mobile devices. Newspaper was an interesting case. Those who were young and those who were old tended to rate newspaper as more credible than those who are in the middle (see Table 4).

Research questions 2-4 examined people's preferred source of information when there were conflicting entertainment/disaster/political news stories. For the type of medium, a series of chi-square analyses showed that there was no significant correlation between the city and the most reliable channel for entertainment/disaster/political news story. Descriptive statistics further confirmed that respondents in the three cities showed the same pattern in this regard. Thus, data were combined to answer the proposed research questions.

Specifically, if there were conflicting reports about the same entertainment story, people were most inclined to believe TV (Tianjin: 57.1\%; Chengdu: 62.2\%; Nanjing: $55.7 \%$ ), followed by websites (Tianjin: 28.8\%; Chengdu: 24.4\%; Nanjing: 28.4\%), newspapers (Tianjin: 9.2\%; Chengdu: 9.5\%; Nanjing: 12.1\%), and magazines (Tianjin: $3.3 \%$; Chengdu: $2.5 \%$; Nanjing: $1.9 \%$ ). Very few people perceived radio or mobile devices to be the most credible.

A similar ranking result was identified for disaster news. The only difference was that radio was perceived more

Table 2. t-tests of magnitude credibility based on education.

\begin{tabular}{|c|c|c|c|c|c|}
\hline & High School & College & $\boldsymbol{t}$ & $\boldsymbol{d}$ \\
\hline \hline Newspaper & $70.82(16.451)$ & $69.25(16.491)$ & 1.823 & 1,453 & .068 \\
\hline TV & $76.72(16.137)$ & $72.34(18.722)$ & 4.919 & 1,530 & $.001 * * *$ \\
\hline Website & $60.39(19.477)$ & $62.49(18.029)$ & -2.057 & 1,127 & $.040^{*}$ \\
\hline Magazine & $58.54(19.676)$ & $57.34(18.264)$ & 1.059 & 1,073 & .290 \\
\hline Radio & $66.87(19.191)$ & $64.30(19.705)$ & 2.168 & 1,073 & .209 \\
\hline Mobile Devices & $56.54(22.251)$ & $54.90(20.743)$ & 1.256 & \\
\hline
\end{tabular}

Note: numbers in parentheses are standard deviations.

Table 3. t-tests of magnitude credibility based on party affiliation.

\begin{tabular}{|c|c|c|c|c|c|}
\hline & Member & Non-Member & $\boldsymbol{t}$ & $\boldsymbol{d}$ \\
\hline \hline Newspaper & $70.78(15.845)$ & $69.85(16.668)$ & 0.872 & 1,483 & .383 \\
\hline TV & $75.22(17.516)$ & $74.48(17.596)$ & 0.666 & 1,557 & .506 \\
\hline Website & $58.93(19.958)$ & $62.09(18.318)$ & -2.498 & 1,366 & $.013^{*}$ \\
\hline Magazine & $57.23(19.106)$ & $57.95(18.973)$ & -.513 & 1,073 & .608 \\
\hline Radio & $66.83(20.516)$ & $65.23(19.077)$ & 1.104 & 1,091 & $.016^{*}$ \\
\hline Mobile Devices & $52.51(21.796)$ & $56.42(21.333)$ & -2.422 & & .270 \\
\hline
\end{tabular}

Note: numbers in parentheses are standard deviations. 
Table 4. ANOVA analyses of magnitude credibility based on age.

\begin{tabular}{|c|c|c|c|c|c|c|}
\hline & 30- & 31-50 & 50+ & $\boldsymbol{F}$ & $\boldsymbol{d}(\mathbf{2}, \boldsymbol{X})$ & 1496 \\
\hline \hline Newspaper & $71.63(15.504)$ & $67.82(17.287)$ & $70.72(16.234)$ & 7.891 & $.001 * * *$ \\
\hline TV & $73.17(18.005)$ & $74.07(18.171)$ & $76.61(16.038)$ & 4.836 & 1557 & $.008 * *$ \\
\hline Website & $64.63(18.542)$ & $60.68(18.350)$ & $57.03(18.994)$ & 16.855 & $.001 * * *$ \\
\hline Magazine & $58.17(19.025)$ & $56.96(18.647)$ & $58.47(18.701)$ & 0.688 & 1132 & .503 \\
\hline Radio & $65.03(18.192)$ & $64.73(20.028)$ & $67.21(19.863)$ & 1.528 & 1086 & .218 \\
\hline Mobile Device & $59.05(20.704)$ & $54.78(20.496)$ & $51.08(22.943)$ & 11.553 & $.001 * * *$ \\
\hline
\end{tabular}

Table 5. Ranks of comparison credibility for the six media types (Percentage of people who considered the medium most credible).

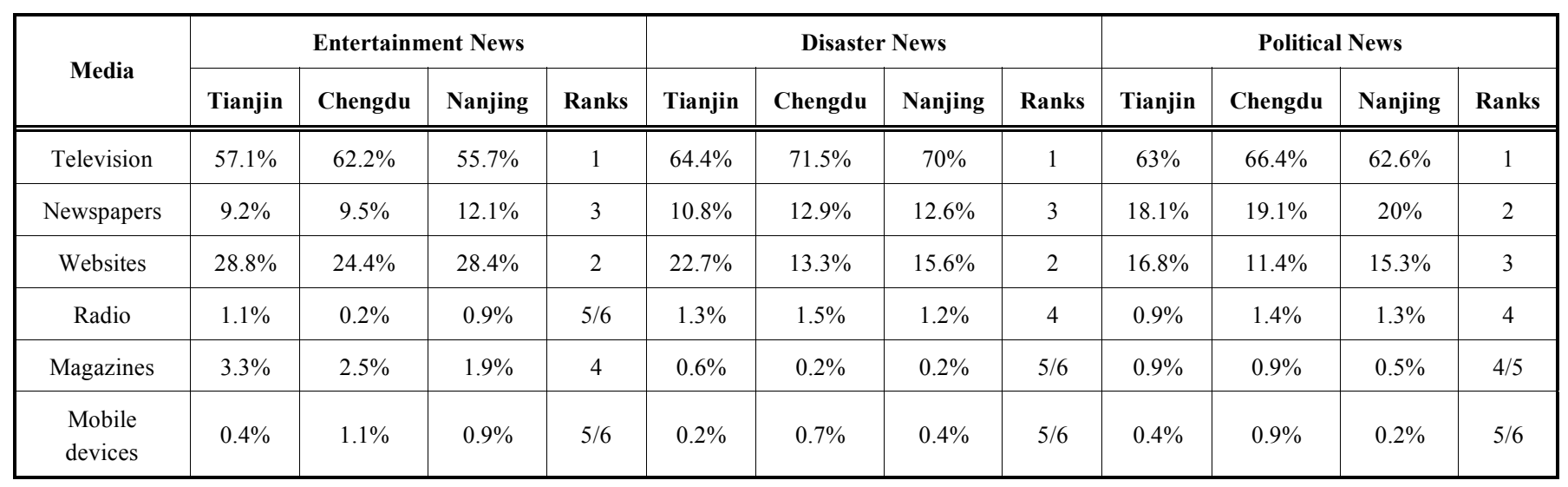

Table 6. Ranks of comparison credibility for the five sources (Percentage of people who considered the source most credible).

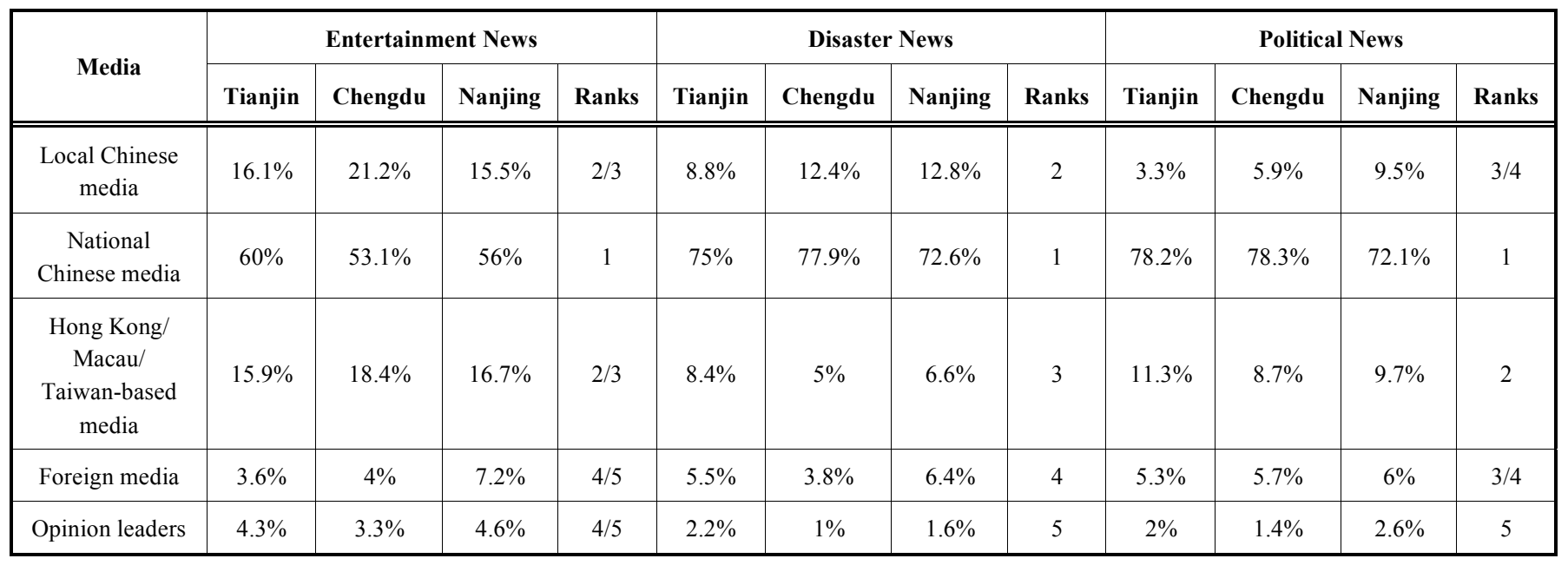

credible than magazines across the three cities. When it came to political news, few people chose radio, magazines, or mobile devices as most credible; TV was still rated as the most believable medium. However, newspapers were perceived more credible than websites across the three cities.

The same research questions also examined whether people would be inclined to believe local Chinese media, national Chinese media, Hong Kong/Macau/Taiwan-based media, foreign media, or opinion leaders, if reports were conflicting. Descriptive statistics showed that people across the three cities were most inclined to believe national Chinese media for entertainment news (Tianjin: 60\%; Chengdu: $53.1 \%$; Nanjing: $56 \%$ ), for disaster news (Tianjin: 75\%; Chengdu: 77.9\%; Nanjing: $72.6 \%$ ), and for political news (Tianjin: 78.2\%; Chengdu: 78.3\%; Nanjing: $72.1 \%$ ). In addition, while people in all three cities chose local Chinese media for disaster news over Hong Kong/Macau/Taiwan-based media, people preferred Hong Kong/Macau/Taiwan-based media to local Chinese media for political news. 


\section{DISCUSSION}

Research results provide ample evidence that people from the three cities perceived television as the most believable and trustworthy medium. The comparison credibility index showed that most of the respondents chose television over other kinds of media, which also earned the highest ratings in the magnitude credibility index across the three cities. Moreover, people ascribed the most credible story to TV if the news reporting was conflicting, regardless of the type of the news-entertainment, disaster, or politics. Similar to many early credibility studies in the U.S. (Gaziano \& McGrath, 1986; Roper Organization, 1979) television led in the ranking, in both comparison and magnitude credibility measures.

Contrary to our assumption, it appears that message type did not have much impact on how people perceived channel credibility and source credibility. Whether the conflicting news story was entertainment, disaster, or politics, most respondents preferred the TV version to versions on newspapers, websites, radio, magazines, or mobile devices. They also trusted the version from national Chinese media more than that from local Chinese media, Hong Kong/Macau/Taiwan-based media, foreign media, or opinion leaders. It is possible that people have a general tendency to trust a government and its media organizations (Lee, 2005; Stroud \& Lee, 2013) found that Americans who trusted both $\mathrm{CNN}$ and FOX also trusted the American government. They also identified a positive correlation between a general distrust in government and an inclination to distrust CNN. Although the explanation here is speculative, it warrants a follow-up study to test the level of trust toward the Chinese government among Chinese citizens to see whether it mediates the relationship between message type (e.g., political news) and channel credibility (e.g., newspapers).

Another possible explanation is related to the strength of an individual's political commitment, which has already been examined in this study when discrepancy was shown between comparison and magnitude credibility measures regarding whether websites or radio were more credible. The examination of people's political affiliation suggested that non-communists perceived websites to be significantly more credible than did communists. It stands to reason that political knowledge and prior commitment to the party may have resulted in a harsher standard set by communists to assess the website credibility, considering the availability of diversified political news angles online. It was also possible that non-communists believed online news sites had a less restrictive gatekeeping system and editorial/censorship policy, thus allowing for less biased political opinions and more interactive news gathering. This partially explained why people preferred Hong Kong/Macau/Taiwan-based media to local Chinese media for political news. Future research can further operationalize the strength of political commitment into apathetic, moderate, and enthusiastic levels, given the one-party political system in China.

The notable discrepancy regarding the ranking of radio and websites from comparison and magnitude measures was interesting. It could be a sample issue in which participants in this sample dictated these results, or it could be a measurement issue, implying that credibility measured in different conceptualizations led to different outcomes. Future explication of the credibility concept and measurement validation in this area is warranted.

Of particular interest is the impact of contingent factors including education level, age and party affiliations. Results showed that those who considered online news most credible were more likely to hold a bachelor's degree or to have better education generally; those who preferred newspapers/TV were more likely to have a high school diploma or even lower education. This pattern was further confirmed when message type was differentiated into entertainment news, disaster news, and political news.

There is no surprise in terms of age and its effect on credibility. Older people tend to trust traditional media such as TV and newspaper more. Younger and more educated people tend to have a higher degree of trust on newer media such as websites and mobile devices.

A few caveats of this study need to be addressed. Respondents of only three cities were interviewed. There are approximately 20 to 30 such cities in mainland China. Thus, an analysis incorporating more cities would provide additional insight. Particularly noteworthy is that demographic factors, such as party affiliation, education, and age, were found influential on people's credibility perceptions. It is possible that these factors affected the results through the mediation of media consumption, as argued by some researchers that people trust the media they use (Stroud \& Lee, 2013). Researchers should examine how media use habits and reliance affect perceived media credibility in the future.

\section{CONFLICT OF INTEREST}

The authors confirm that this article content has no conflict of interest.

\section{ACKNOWLEDGEMENTS}

Declared none.

\section{REFERENCES}

Carter, R.F., \& Greenberg, B.S. (1965). Newspaper or television: Which do you believe? Journalism Quarterly, 42, 29-34.

Chung, C.J., Nam, Y., \& Stefanone, M.A. (2012). Exploring online news credibility: The relative influence of traditional and technological factors. Journal of Computer-Mediated Communication, 17(1), 171-186.

Flanagin, A.J., \& Metzger, M.J. (2007). The role of site features, user attributes, and information verification behaviors on the perceived credibility of web-based information. News Media \& Society, 9, 319-342.

Gallup. (2011). Confidence in Institutions. Retrieved on: $18^{\text {th }}$ March, 2014 from http://www.gallup.com/poll/1597/confidence-institutions.aspx

Gaziano, A.C., \& McGrath, K. (1986). Measuring the concept of credibility. Journalism Quarterly, 63, 451-462.

Hovland, C.I., \& Weiss, W. (1951). The influence of source credibility on communication effectiveness. Public Opinion Quarterly, 15, 633650 .

Jensen, J., \& Hurley, R. (2012). Conflicting stories about public scientific controversies: Effects of news convergence and divergence on scientists' credibility. Public Understanding of Science, 21(6), 689704.

Johnson, T.J., \& Kaye, B.K. (2000). Using is believing: The influence of reliance on the credibility of online political information among politically interested Internet users. Journalism and Mass Communication Quarterly, 77, 865-879.

Kiousis, S. (2001). Public trust or mistrust? Perceptions of media credibility in the information age. Mass Communication \& Society, 4, 381403. 
Lee, T. (2005). The liberal media myth revisited: An examination of factors predicting trust. American Behavioral Scientist, 54(1), 8-21.

MacMurchy, C. (2009, January 12). China Spends 45 Billion to Extend Media's Global Reach. Retrieved on: $23^{\text {rd }}$ March, 2013 from http://www.zhongnanhaiblog.com/web/articles/353/1/Chinaspends-45-billion-to-extend-medias-global-reach/Page1.html

Major, A.M., \& Atwood, L.E. (1997). Changes in media credibility when a predicted disaster doesn't happen. Journalism Quarterly, 74, 797813.

Mandelli, A. \& Vianello, S. (2010) Channel credibility of the Internet as a bundle of different media (2010). Available at Social Science Research Network: http://ssrn.com/abstract=1687325

Metzger, M.J., Flanagin, A.J., Eyal, K., Lemus, D.R., \& McCann, R. (2003). Credibility in the $21^{\text {st }}$ century: Integrating perspectives on source, message, and media credibility in the contemporary media environment. Communication Yearbook, 27, 293-335.

Pew Research Center. (2010, September 12). Americans spending more time following the news. Retrieved on: $25^{\text {th }}$ March, 2013 from http://www.people-press.org/2010/09/12/americans-spendingmore-timefollowing-the-news/

Reporters without Borders. (2013). 2013 World Press Freedom Index: Dashed hopes after spring. Retrieved on: $23^{\text {rd }}$ March, 2013 from http://en.rsf.org/press-freedom-index-2013,1054.html
Robinson, M.J., \& Kohut, A. (1988). Believability and the press. Public Opinion Quarterly, 52, 174-189.

Roper Organization. (1979). Public perceptions of television and other mass media: A twenty-year review 1959-1978. New York: Television Information Office.

Schmierbach, M., \& Oeldorf-Hirsch, A. (2012). A little bird told me, so I didn't believe it: Twitter, credibility, and issue perceptions. Communication Quarterly, 60(3), 317-337.

Stacks, D.W., \& Salwen, M.B. (2009). An integrated approach to communication theory and research. New York: Routledge.

Stroud, N.J., \& Lee, J.K. (2013). Perceptions of cable news credibility. Mass Communication and Society, 16, 67-88.

Wesley, B.H. \& Severin, W.J. (1964). Some correlates of media credibility. Journalism Quarterly, 4, 325-335.

Westerman, D., Spence, P., \& Van Der Heide, B. (2013). Social media as information source: Revency of updates and credibility of information. Journal of Computer-Mediated Communicaiton, 19(2), 171-183.

Yuan, E. (2011). News consumption across multiple platforms. Information, Communication \& Society, 14(7), 998-1016.

Received: March 02, 2014

Revised: May 06, 2014

Accepted: May 12, 2014

(C) Zhou et al.; Licensee Bentham Open.

This is an open access article licensed under the terms of the Creative Commons Attribution Non-Commercial License (http:/creativecommons.org/licenses/by-nc/3.0/) which permits unrestricted, non-commercial use, distribution and reproduction in any medium, provided the work is properly cited. 